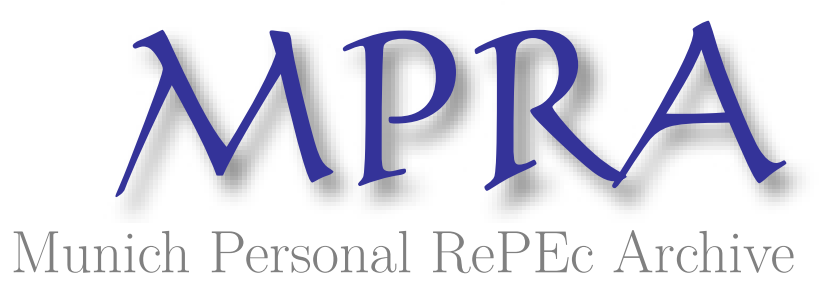

\title{
A Typology of Economic Instruments and Methods for Efficient Water Resources Management in Arid and Semi-Arid Regions
}

Karousakis, Katia and Koundouri, Phoebe

2006

Online at https://mpra.ub.uni-muenchen.de/41909/

MPRA Paper No. 41909, posted 12 Oct 2012 20:22 UTC 


\title{
A Typology of Economic Instruments and Methods for Efficient Water Resources Management in Arid and Semi-Arid Regions
}

\author{
Katia Karousakis* and Phoebe Koundouri** \\ * University College London \\ ** University of Reading and University College London
}

\section{Introduction}

Water scarcity issues are a cause for serious concern in arid and semi-arid regions and existing water shortages are predicted to escalate in both frequency and duration over the next century (UNEP, 2003). Global water consumption grew sixfold between 1900 and 1995, more than double the rate of population growth, and continues to rise with growing farming, industry, and domestic demand. By 2025, the number of countries qualifying as water scarce is anticipated to rise to 35 (from 20 in 1990). Given that water provides one of the most important life-support functions, ensuring food security through agricultural production and enabling the existence of all ecosystems, the allocation of scarce surface and groundwater resources in an efficient manner is of paramount importance. The significance of groundwater resources should not be underestimated as this resource represents around $90 \%$ of the world's readily available freshwater resources and some 1.5 billion people depend upon it for drinking water. In addition to the quantitative shortages of water resulting from demand and supply imbalances, water scarcity in arid and semiarid regions is further exacerbated by deteriorating water quality caused by point and non-point source pollution.

In Europe, industry accounts for $54 \%$ of total water consumption, agricultural water use accounts for about $33 \%$, while $13 \%$ is used for domestic purposes. The driving forces of water demand are strongly linked with national and international social and economic policies, and additional forces of water shortages are due to natural variability in water 
availability (rainfall) and changes in Europe's climate. These cases are most pronounced in the Mediterranean and as can be seen from the case studies provided in previous chapters in this book (Cyprus, Crete, Sicily, Corsica and Mallorca), in many areas conflicting demands for water in different sectors is resulting in unsustainable water use or is at risk of over-extraction. Water scarcity problems can constitute a threat to sustainable development and have major environmental, social, economic, and political repercussions. Typical consequences associated with water scarcity include water surface exploitation, reservoir and lake eutrophication, aquifer exploitation, minimum and ecological flow, and desertification and erosion in basins, among other things (EEA, 1996).

The need for an integrated approach to water resources management has thus become increasingly evident over the past years. In response to this, EU legislation has striven to develop on a more comprehensive approach culminating in the EU Water Framework Directive (WFD). The Directive establishes a framework for the protection of all water bodies (including inland surface waters, transitional waters, coastal water and groundwater). The key objective is to achieve good water status for all waters by 2015.

This chapter provides the economic perspective to implementing integrated water resources management and describes the valuation techniques and economic instruments that have been developed and are available to help price water efficiently, and allocate it to it's highest valued user.

\section{A Manual for Implementing Integrated Water Management: The Economic Perspective}

The implementation of an integrated water management framework from an economic perspective can be described in a three step approach consisting of:

1. The economic characterization of water in the region,

2. The assessment of the recovery of the costs of water services, and 
3. The economic assessment of potential measures for balancing water demand and supply.

A comprehensive economic characterization of the water in the region requires first of all that the economic significance of water in the region is evaluated. This involves an assessment of the residential, industrial, agricultural and tourism water needs in the area. This will include information on the population connected to public water supply system vs those with self-supply, the total cropped area, cropping patterns, gross production and income of the farming population for the agricultural sector, and the total number of tourist days and employment and turnover in the tourism sector. The key economic drivers influencing pressures and water uses need to be determined including (a) the general socio-economic indicators such as population growth, income, and employment; (b) the key sector policies that significantly influence water use (e.g., agricultural and environmental policies); (c) the development of planned investments likely to affect water availability; and (d) the implementation of future policies (environmental and other) that is likely to affect water use. These economic drivers will need to be accounted in a dynamic perspective, i.e., to determine how these are likely to evolve over time. The final component of the economic characterization of water in a region is the application of appropriate methodologies to assess sector-specific water demand. This involves deriving the marginal value of water in consumption and production, the price and income elasticity of demand, the marginal and average willingness to pay for public goods and quality changes of common access resources, and the associated risk parameters

The second step in implementing integrated water management is to conduct a costrecovery assessment of water services. This involves identifying the current water services costs by sector and the users and or institutions that bear them. For example, operation and maintenance costs are often subsidized by the government and frequently, the social opportunity costs and external costs of extracting surface and groundwater are not reflected in market prices at all. Current cost-recovery levels must also be determined incorporating all financial, environmental and resource costs and the institutional set-up 
for cost-recovery such as the price and tariff structure, the existence of direct and indirect subsidies and cross-subsidies. If cost-recovery is incomplete, the potential mechanisms available for this include taxes on water abstraction, charges for the use of the irrigation system, the selling of permits for water abstraction, etc. Clearly, affordability for water users is also an important objective, and potential measures to address equity will also need to be identified. These may include subsidies to low-income households (mainly for agricultural water use) and capital subsidies on investments on infrastructure.

The third and final step is to conduct an economic assessment of potential measures for balancing water supply and demand. Least-cost measures may include the use of economic instruments such as abstraction and pollution taxes, tradable permits; alternative measures to increase awareness regarding water scarcity; the use of direct controls on pollution charges to alleviate water quality issues; and the use of agrienvironmental programs to provide financial and technical assistance such as the adoption of water-saving technologies. These least-cost measures need to be assessed in terms of financial costs (capital, operation and maintenance, and administrative costs) and indirect costs (changes in environmental quality and the costs of preventative and mitigation measures). Finally, the impacts of these measures on key economic sectors and uses need to be evaluated. This includes the net impacts on public expenditures and revenues and the wider economic and social impacts such as on patterns of employment.

In the case that the achievement of good water status has significant adverse effects on the wider environment and human activities, then this constitutes 'disproportionality' in which case there may be time derogations or else the application of less stringent objectives may be applied.

The following section provides an overview of the market and government failures leading to the unsustainable use of water resources, in terms of over-exploitation and excessive pollution. This provides a backdrop for section 4 which presents a typology of economic instruments and measures that are available for efficient surface and groundwater water resources management from both a water quantity and water quality 
perspective. The advantages and limitations of these are identified and examples of where these have been implemented are described.

\section{Market Failures in Water Resources Management and Optimal Use}

\subsection{Market and Government Failures}

Water services are public goods, that is, provision to one individual does not prevent others from using it. This is a form of market failure and can result in under-investment and misallocation of resources. Other water services are characterized by economies of scale, which can lead to monopolistic power and socially inefficient allocation.

For groundwater the prevailing externalities are of a different sort. Exploitation of a stock of groundwater is typically a common property problem since there is limited access to the resource. The finite stock implies that each unit of groundwater is extracted is no longer available for others to use, therefore there is little incentive to save water for future use, which in turn leads to overpumping. Provencher and Burt (1993) call this the stock externality. In addition, there is a pumping cost externality: As the water table declines with increasing extraction, the pumping cost to the firm increases, as do the pumping costs of the other firms exploiting the resource. Since a firm does not take the other firms costs into account, a second externality is generated. Finally, is the risk externality, which is caused by the inherent value of groundwater as a substitute source of water in times of surface water shortages.

With regard to surface and groundwater quality, excessive pollution is caused by the existence of environmental externalities. Examples include effluent from waste treatment plants, factories, and urban and agricultural run-off. In these cases, the social costs of producing the good is ignored, leading to artificially low production costs and hence over-production of the good that generates the externality. 
Importantly, economic decisions need to be made compatible with social objectives, i.e. efficiency and equity considerations. Equity refers to the distribution of wealth among sectors and individuals. Government failures can also lead to misallocation of resources as for example subsidies for agricultural production leading to the over-exploitation of water resources for irrigation purposes.

\subsection{Optimal Allocation of Scarce Water Resources}

As a result of the above forementioned issues, water supply and demand imbalances occur and water is not allocated efficiently amongst the resource users. Allocative efficiency requires the marginal value of water to be the same for the last unit of water consumed by each user and that it is equal to the cost of supplying water. Otherwise, society would benefit by allocating water to another sector where the returns would be higher. The efficiency criterion maximizes the total value of production across all affected sectors of the economy. There are spatial and temporal considerations that need to be taken into account when valuing water which vary according to the quality and it's use, thus making water a more challenging resource to manage efficiently.

The optimal price of water is illustrated in figure 1 below. If there is a single source of water with several users at different locations then the marginal private cost (MPC) of water at the source is the cost of operating the facility plus the user cost. The marginal cost of water at a more distant location is the MPC (as before) plus the marginal cost of transporting the water from the source to the user, also know as the marginal conveyance cost (MCC). There are also environmental costs associated with removing water from a lake or a reservoir as this may have detrimental impacts on fish populations and other wildlife. The marginal environmental costs are denoted by MEC. Finally there may also be future costs associated with the extraction of water due to uncertainty in precipitation, denoted here by MFC. Examples of these costs include reduction in future productivity due to accumulation processes such as soil salinity or water logging. 


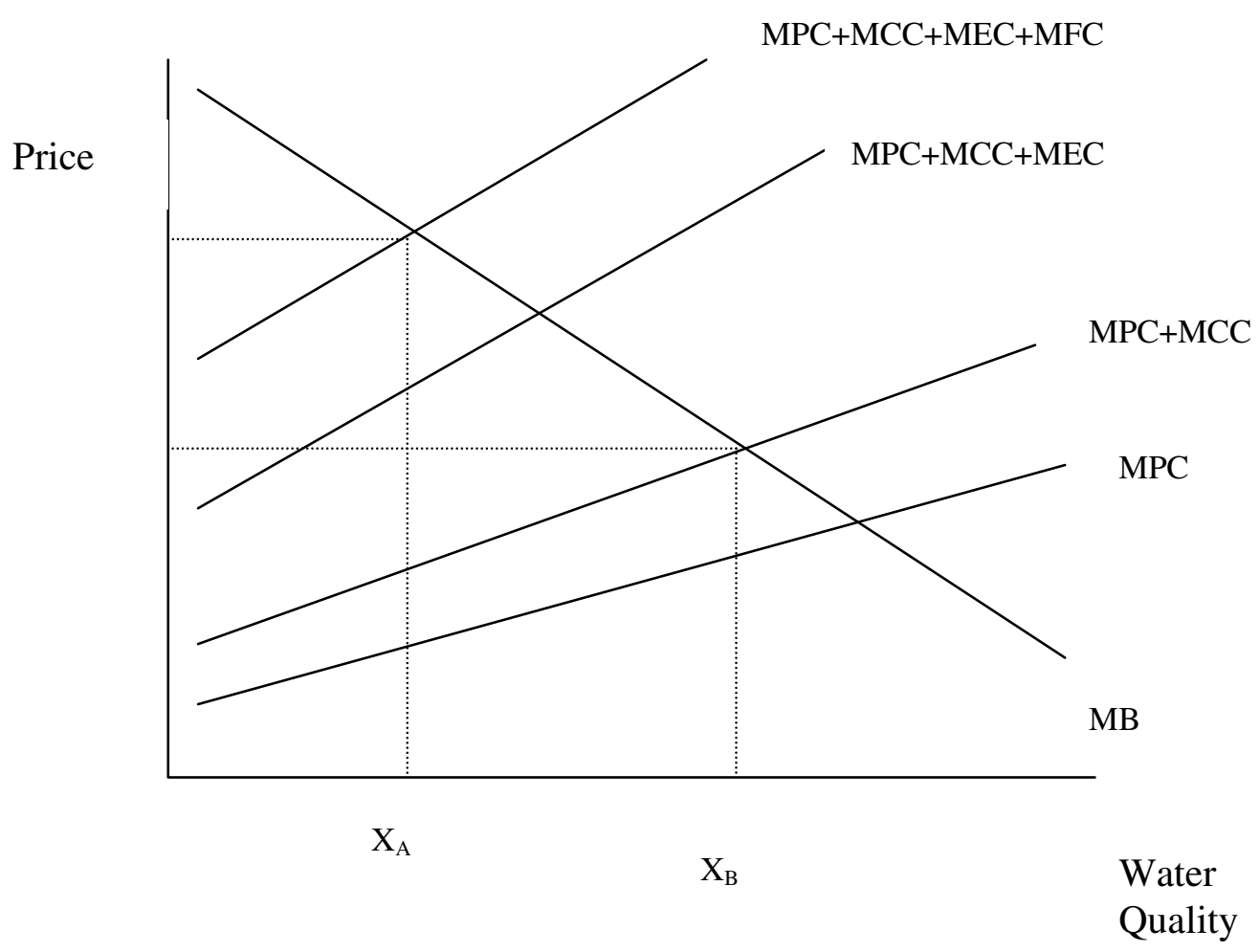

MB is the marginal benefit curve and reflects the economic benefits that water buyers obtain from purchasing water. The intersection of demand (MB) with the sum of all costs reflect the socially optimum outcome where the amount of water extracted/used is given by quantity $\mathrm{X}_{\mathrm{A}}$. However, in most cases future and externality costs are not normally taken into account, leading to an equilibrium at point $\mathrm{B}$, where the amount of water extracted/used is $X_{B}$, which is inefficiently high.

Source: D. Zilberman and K. Schoengold, 2005

\subsubsection{Non-Market Valuation Techniques}

In part as a result of these market and government failures, degradation and loss of the environmental functions of water resources has been prolific in the last century. However, due to the observed loss of many ecological and hydrological services formerly provided 
free by aquatic systems and the consequent environmental and economic costs of this loss, aquatic system protection and conservation has become an internationally important political issue.

In any aquatic system a number of processes may be occurring to a greater or lesser extent. These may be of a physical, chemical, biological or ecological nature. As a consequence of the occurrence of such processes, aquifers will perform a number of ecosystem preservation functions. For example, the process of water storage in an aquifer may result in a wetland, which is performing the function of flood attenuation, while the processes of denitrification and plant nutrient uptake may contribute to the ability to perform the function of water quality maintenance through the removal of nutrients from surface water and shallow groundwater. Plant uptake of nutrients may also result in the performance of other functions such as the provision of support to the food web and habitat, demonstrating that an individual process may contribute to a variety of wetland functions.

The benefits of these water resources functions to the society (and social welfare), however, is not confined to their physical functions referred in the previous paragraph. For example, they may be supporting wetlands used for recreation such as sailing, shooting and fishing; be held dear as intrinsic parts of landscapes or as wild places; and be valued, as habitats, for their biodiversity. Moreover, water storage in aquifers may provide direct economic benefits but the value of aquatic systems, like that of nature in general, also has cultural and social dimensions. Such values, constituted through social processes, represent as much ethical, aesthetic and cultural concerns as scientific knowledge. In particular, nature's popular significance resides largely in meanings and values other than those bestowed by scientific understanding. But, the physical functions performed by an aquatic system take place with or without the presence of society, usually as part of a self sustaining ecosystem (intrinsic features), whereas other aquatic systems values require the presence of society (extrinsic features), and these will vary over time and space while the functions may not.

Although the sources of aquatic system values are diverse and heterogeneous, much of national policy all over the world relating to aquatic systems (if existent at all) has arisen 
solely from scientific reports, which in some cases are flawed or only locally applicable. It is now widely accepted that decisions about environmental and groundwater resource management related policies and projects should not be made on scientific and/or economic (including financial, management, restoration costs and benefits) grounds alone; social and cultural aspects also need to be heeded. For the integration of these values policymakers have to explore water values held by 'ordinary' citizens in the context of developing a nonmonetary approach to valuation and suggest how these values should be integrated in water resources management policies.

Figure 1: A simple framework relating water resources to environmental functions, human benefits and anthropocentric values

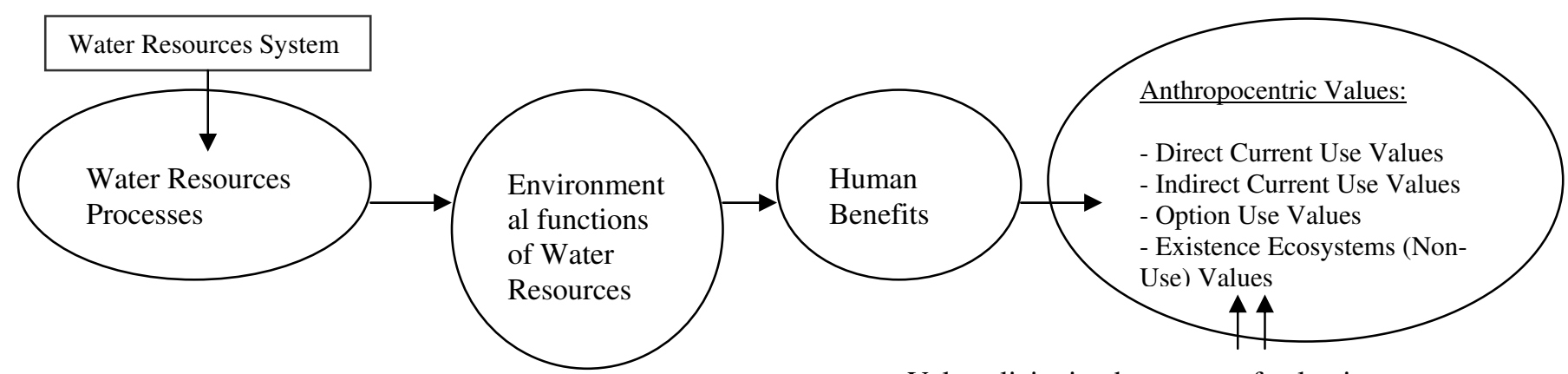

Value elicitation by means of valuation methods:

- Hedonic Pricing

- Tavel Cost Pricing

- Residual Analysis

- Replacement/Restoration Cost Method

- Contingent Valuation

- Choice Experiments

- Meta-analysis

In economics, the basis of value is determined by individual preferences. Preferences reflect the utilities that are expected to be derived from the consumption of resources, given the needs, wants and wishes of consumers. In order to correctly evaluate a given resource, one needs to consider the Total Economic Value (TEV) of the resource i.e., the whole class of values that have a basis in human preferences. TEV is composed of direct and indirect use values, as well as non-use values. Current use value derives from the 
utility gained by an individual from the consumption of a good or service, or from the consumption of others (e.g. parents may obtain utility from their children's consumption). Current use value is composed of direct use value (commercial and recreational) and indirect use value (such as amenity value or general ecosystem support). Option Value derives from retaining an option to a good or service for which future demand is uncertain. If we are not certain about either our future preferences or about future availability, we may be willing to pay a premium (the option value) to keep the option of future use open. The option value an additional value to any utility that may arise if and when the good is actually consumed.

Existence Value derives from human preferences for the existence of resources as such, unrelated to any use too which such resources may be put. Individual preferences may exist for maintaining resources in their present forms even where no actual or future 'use' is expected to be made of the resource.

Given that many of these components of value are not reflected in market prices of water, economists will attempt to estimate the true resource value through user willingness to pay (WTP) for a given quantity and quality of supply. Valuation techniques are therefore necessary to assign appropriate prices that will enable water to be allocated in the most efficient manner. A variety of these techniques have been developed over the years to address this issue and are generally classified as revealed preference techniques and stated preference techniques. ${ }^{1}$ Revealed preference techniques use data on goods or services that are marketed and do have observable prices, in order to value some environmental attribute, which is embodied in the marketed goods and services, but is not traded itself in any particular market. In stated preference techniques, individuals are provided with a constructed scenario in which they are asked how much they are willing to pay to changes in environmental quantity.

\footnotetext{
${ }^{1}$ A comprehensive and state of the art review of valuation techniques and relevant empirical applications from Europe and the rest of the world can be found in Koundouri (2005).
} 
Within the category of revealed preference techniques for water resources, one approach is the residual value method which values all inputs for the good produced at market price, except for the water resource itself. The residual value of the good is attributed to the water input. For example, one can value water as an input in the production of different crops. A problem with this methodology is that only part of the use value of water can be captured.

Another approach is the hedonic pricing method whereby implicit prices of characteristics which differentiate closely related goods are estimated [Griliches, 1971; Rosen, 1974]. Suppose that an environmental resource that you wish to value is not itself traded in any market, possibly because the resource is a public good. As a result, no market price exists which can reveal preferences or willingness to pay for the resource. Suppose also that the resource can be defined in terms of services it yields or an 'attribute' it embodies. This attribute may be embodied in other goods or assets which are marketed, and which do have observable prices. For example, farm prices in an area with good groundwater availability will be higher than areas with little or no groundwater availability. By comparing farm prices in different areas and accounting for other differences, the remaining difference in farm price can be attributed to groundwater availability. An example of hedonic pricing applied to evaluate water quality in Cyprus is given by Koundouri and Pashardes (2003). Using data on 193 parcels of land on variables such as price, usage (agriculture vs tourism), proximity to the sea, and other variables, they estimate the marginal willingness to pay to avoid a marginal increase in the salinization of fresh groundwater supplies beneath owner's land.

A limitation of the hedonic pricing technique is that it is only capable of measuring that subset of use values for which people are willing to pay and do so indirectly through the related market. It also relies on the assumption that consumers are fully informed about the qualities of the attributes being valued, otherwise hedonic price estimates are of little relevance. There are other problems in that the hedonic price equation and the secondstep demand equation impose rather strong assumptions about separability of consumers' utility functions. The functional forms of regression models that are usually chosen 
impose weak separability, permitting rent-pollution and demand functions to be estimated independently of demand equations for other goods that consumers purchase. However, standard consumer demand theory and evidence from applied studies doubt the validity of weak separability, particularly when large changes occur, as is often the case when dealing with environmental projects.

Travel cost models (also known as recreation demand models) is an alternative revealed preference technique which focuses on choice of trips or visits for recreational purposes and looks at the level of satisfaction, time, and money spent in relation to the activity. Patterns of travel to a particular sight can be used to analyze how individuals value the site and for example, the water quality of a river stretch. See Bockstael et al (1987) for an example.

Within the category of stated preference techniques, one can use contingent valuation methods, choice modeling approaches, and meta-analysis. Many water quality evaluation problems occur in a framework for which no value measures can be derived from observing individual choices through a market. This is mainly due to the public good aspect of groundwater quality. Other examples where actual consumer choices are unobservable are cases where the policy change is potential rather than actual. In such cases, respondents are offered conditions simulating a hypothetical market in which they are asked to express willingness to pay for existing or potential environmental conditions not registered on any market. The most common form of questioning on hypothetical futures is called the Contingent Valuation Method (CVM). This involves asking individuals directly what they would be willing to pay contingent on some hypothetical change in the future state of the world (Mitchell and Carson, 1989). Alternatively, this can be expressed as the minimum monetary compensation they would accept to go without an increase in that good or tolerate a decrease (willingness to accept compensation WTA). Thus, an individual's WTP or WTAC will depend on the description of the contingent market, the information they have about the environmental good, (which depends partly on what they are told about it as part of the CVM survey, their own preferences and their budget constraints, and the availability of substitutes and 
complements. In brief, a CVM exercise consists of a description of the environmental change in question and the contingent market, establishing a bid vehicle (e.g. an increase in monthly water bills), and a reason for payment (e.g. to reduce water shortage incidents from three times a month to once a month). The WTP bids can be elicited in a variety of methods including an open-ended format, a bidding game, a payment card or a single or double-bounded dichotomous choice mechanism. Once the mean and median WTP has been estimated, the average bid can be aggregated to a population total value.

There are many problems associated with CVM that may bias the value estimates (e.g. interviewing bias, non-response bias, strategic bias, embedding effects, yea-saying bias, hypothetical bias, information bias), and best practice guidelines for conducting CVM studies have been developed (NOAA, 1993). These recommend for example the use of dichotomous choice formats over other alternatives, that in-person interviews should be conducted as opposed to e.g. mail surveys, and that WTP, not WTAC, measures should be elicited.

Partly as a response to these problems, valuation practitioners are increasingly interested in alternative stated preference formats such as Choice Modeling (CM). CM is a family of survey-based methodologies (including choice experiments, contingent ranking, contingent rating and paired comparisons) for modeling preferences for goods, which can be described in terms of their attributes and of the levels they take. Respondents are asked to rank, rate or chose their most preferred alternative. By including price/cost as one of the attributes of the good, willingness to pay can be indirectly recovered from people's rankings, ratings or choices. An excellent critical review of CM alternatives and investigation of their potential to solve some of the major biases associated with standard CVM is provided by Hanley et al. (2001). In the class of CM alternatives, probably the one receiving the most attention is the choice experiment method (CEM). This is a survey-based technique which can estimate the total economic value of an environmental stock/flow or service and the value of its attributes, as well as the value of more complex changes in several attributes. Each respondent is presented with a series of alternatives of the environmental stock/flow or service with varying levels of its attributes and asked to 
choose their most preferred alternative in each set of alternatives. CEM eliminates or minimises several of the CVM problems (e.g. strategic bias, yea-saying bias, embedding effects). An example of a choice experiment method applied to wetlands evaluation is that of Carlsson et al. (2003), who estimate the values of both use and non-use values of Staffanstorp wetland in Sweden. The selection of attributes and levels that they select include biodiversity (low, medium, high), fish (yes, no), surrounding vegetation (forest, meadow), walking facilities (yes, no), and a cost attribute (varying from SEK 200-850). The choice sets are then constructed using experimental design methods and the survey sent out via mail to 1200 randomly selected individuals living in Staffanstorp. Using econometric models, they find that biodiversity levels and walking facilities are the two greatest contributors to welfare, whereas some other attributes led to a decline in welfare.

Recent years have seen a growing interest, both from academics and policy makers, in the potential for producing generally applicable models for the valuation of non-market environmental goods and services, which do not rely upon expensive and timeconsuming original survey work, but rather extrapolate results from previous studies of similar assets. Such methods are called meta-analysis for the use and non-use values generated by environmental resources. Meta-analysis is the statistical analysis of the summary of findings of empirical studies, that is, the statistical analysis of a large collection of results from individual studies for the purpose of integrating the findings. Meta-analysis offers a transparent structure with which to understand underlying patterns of assumptions, relations and causalities, so permitting the derivation of useful generalizations without violating more useful contingent or interactive conclusions.

The increase in meta-analytical research seems to have been principally triggered by:

1. Increases in the available number of environmental valuation studies;

2. The seemingly large differences in valuation outcomes as a result of the use of different research designs;

3. The relatively high costs of carrying out environmental valuation studies and the increasing demand for transferable valuation results. 
Brouwer et al 2004 present such a meta-analysis for the use and non-use values generated by wetlands across Europe and North America.

As can be seen, each of the valuation have advantages and disadvantages associated with them, and depending on the component of total economic value one is trying to estimate, some methods are more suitable than others. Once realistic estimates of surface and groundwater values are available, it is then necessary for governments to determine which policy measures are most suitable to achieve the desired outcomes.

\section{Economic Instruments for Efficient Surface and Groundwater Management}

A number of economic instruments are available that can provide the appropriate incentives for efficient surface and groundwater resources extraction and management. Though economic instruments to manage surface water and groundwater are similar, they are not identical due to certain special characteristics associated with groundwater. These include the relatively high cost and complexity of assessing groundwater, the highly decentralized nature of resource use and the ensuing high monitoring costs, and the long time-lags and near irreversibility of most aquifer contamination. The selection and use of economic instrument will also depend on current hydrology, economic, social, and political considerations.

\subsection{Standards and Quotas}

A legal water standard or quota can be introduced that places restrictions on the amount of water that can be extracted for use. It will be effective if water users face substantial monetary penalties for lowering the water level below this standard or not adhering to the quota. Water quality standards may also be established. Standards and quotas do not strictly qualify as economic instruments as they do not improve economic efficiency and do not introduce incentives to innovate. The financial impact is not always equitably distributed among affected parties, since there are differences in the vulnerability of areas to changes induced by these instruments. Differentiated standards and quotas, however, 
will pose a large burden on the administrative capacity. Usually serious resistance is raised against the introduction of these policy instruments.

\subsection{Water Abstraction Taxes}

Theoretically a tax can be used to restrain water users from lowering the surface or groundwater level below a certain standard.

Area pricing is probably the most common form of water pricing whereby users are charged for water used per irrigated area, and may depend on crop choice, the extent of crop irrigated, and the irrigation method and season. In contrast, output pricing and input pricing are probably the least common forms of water pricing. Output pricing methods involve charging a fee for each unit of output produced per user whereas input pricing involves charging users for water consumption through a tax on inputs, e.g. a charge for each kilogram of fertilizer purchased.

The efficiency of water abstraction taxes is relative and depends on technical and institutional factors. Volumetric pricing is the optimal water tariff where price is equal to marginal cost of supplying the last unit. The choice of water pricing method however will also depend on factors such as institutions, administration and monitoring capabilities, the establishment and control of metering devices, the ability to collect fees, as well as enforcement issues. There are difficulties associated with marginal cost (MC) pricing because MC is multidimensional, i.e., it includes several inputs such as water quantity and quality, and the fact that MC varies over the time period measured (i.e., short-run vs long-run $\mathrm{MC})$.

When sophisticated monitoring technology is available, then tiered pricing, and two-part tariffs (fixed and volumetric) are feasibly introduced. Tiered pricing for irrigation water for example is common in Israel (Yaron, 1997). This was initially introduced in 1974 but then abandoned in 1977 due to farmers political pressure. Agricultural tier pricing was reintroduced in 1989 however and continues to be in effect today. For water from Mekerot, the national water company, farmers pay a progressively increasing price for the first 50 , 
second 30, and final 20 percent of their water quota. Farmers using more water than their quota provides pay much more for the excess. To avoid these punitive charges, farmers generally partake in interfarm transfers of water. By allocating some water through quotas, it is believed that socially undesirable outcomes with respect to the distributional issues are prevented.

The effectiveness of a tax depends on the correct estimation of the marginal tax level and on how risk averse farmers are with respect to damage from reduced water availability (both in quality and quantity terms). A differentiated tax level has to be created, because of local differences in both the monetary value of reserves and vulnerability of the environment to changes in the groundwater level. An advantage of a tax is that it improves both economic and technical efficiency. Administrative costs are high, since a differentiated tax is not easy to control and monitor. The financial impact on affected parties depends on the restitution of revenues, which affects tax acceptability. Finally there are practical implementation problems. It is hard to define a good basis for a tax. A volumetric tax on extraction is complicated, since it involves high monitoring costs. A tax on a change in the groundwater level is also complicated, because external and stochastic factors affect the level of groundwater, which is not uniform across any given aquifer. Charging water-boards for lowering surface water levels will not influence an individuals farmer's behavior, but it will affect the strategy of groups of farmers represented in the governing body of water-boards.

Specific taxes for groundwater abstraction have been adopted in the Netherlands and in France (OECD, 2002). In the Netherlands this was introduced in January 1995 at a standard rate of $0.15 \mathrm{euro} / \mathrm{m} 3$, and at a rate of $0.025 \mathrm{euro} / \mathrm{m} 3$ for infiltrated groundwater.

\subsection{Pollution taxes}

Pollution taxes represent an efficient method of addressing water quality problems if these are adopted at the optimum level. Pigouvian taxes are statically and dynamically efficient as they induce users to innovate. Pollution taxes to address groundwater pollution have been implemented in the Netherlands, Sweden and Denmark, where they 
are targeted at non-point source pollution from agriculture, and are imposed on nitrogen fertilizers.

\subsection{Subsidies}

Subsidies can be directly implemented for water saving measures to induce users to behave in a more environmentally friendly way. Alternatively, indirect subsidy schemes also exist which include tax concessions and allowances, and guaranteed minimum prices. Subsidies however are not economically efficient, they create distortions and do not provide incentives for the adoption of modern technologies. Acceptability, however is not an issue, since participation in subsidy schemes is voluntary and has positive financial implications.

\subsection{Tradable permits}

Another instrument prescribed by economists in the face of demand-supply imbalances is the introduction of water markets (Anderson and Hill, 1997; Howitt, 1997) in which water rights, or permits, can be traded. The rationale behind water allocation through tradable rights is that in a perfectly competitive market, permits will flow to their highest value use (Tietenberg, 2000). Different types of tradable permit systems can be established which address different aspects of the water resource problem (Kraemer and Banholzer, 1999). These are:

- Tradable water abstraction rights for quantitative water resource management. These can permanent and unlimited (property rights to the water resource) or temporary and limited (transferable rights to sue water without right of abuse).

- Tradable discharge permits for the protection and management of (surface) water quality. Such pollution permits can be allocated to point or to non-point sources and trades can also be arranged among different kinds of sources. (For examples from the U.S.A. and Australia, see Kraemer et al 2003)

- Tradable permits to use or consume water-borne resources such as fish or the potential energy of water at height for example. 
Generally, the government will determine the optimal level of water resource use over a specified time period (e.g., annually or seasonally) and will allocated a limited number of permits that reflect the optimal level to the different water users. Permit holders that gain lower benefits from using their permits (due to e.g. higher costs) have an incentive to sell them to users who value them more. The sale results in mutual benefit as each user is better off.

The financial impact on affected parties and related acceptability of tradable permits depends on the initial allocation of rights. These can either be distributed for free (e.g. depending on historical use or other criteria), or auctioned off to the highest bidders. If they are auctioned, revenues are created that the government can earmark for other environmental purposes. The use of tradable rights for groundwater seems to be complicated in practice, since the impact of changes in the groundwater level on agricultural production and nature depends on location specific circumstances. To avoid transferring rights among areas with heterogeneous characteristics, trading has to be restricted.

Tradable water permit systems have been implemented in a number of countries including Chile, Mexico, Peru, Brazil, Spain, several states in Australia, and the Northern Colorado Water Conservancy District in the U.S.A (Marino and Kemper, 1999).

\subsection{Voluntary Agreements}

Another policy option for controlling surface and groundwater use are voluntary agreements between farmers and government organizations. Participation in such control programs is encouraged by means of positive incentives (a restitution of taxes). Such programs try to convince farmers (through education) of the advantages of fine-tuned groundwater control. Voluntary agreements on controlling groundwater use are efficient, since they rely on specialized knowledge of participants about local conditions. When costs and benefits are not equitably distributed among affected parties, both parties can bargain about compensation payments. The allocation of such payments depends on the assignment of rights. Acceptability is not an issue, since it is a voluntary regime. Because 
of these advantages, participation of farmers in planning and decision-making at the local level is becoming more common. The principle of allowing the individual members of agricultural organization and water boards to make decisions on issues that affect them rather than leaving those decisions to be made by the whole group, the so-called 'principle of subsidiary', is widely accepted.

\subsection{Liability for Damage}

Environmental liability systems intend to internalize and recover the costs of environmental damage through legal action and to make polluters pay for the damage their pollution causes. If the penalties are sufficiently high, and enforcement is effective, liability for damage can provide incentives for taking preventative measures. For liability to be effective, there need to be one or more identifiable actors (polluters); the damage needs to be concrete and quantifiable; and a causal link needs to be established between the damage and the identified polluter.

Table 1

\begin{tabular}{|c|c|c|}
\hline \multicolumn{3}{|c|}{ Classification of Economic Instruments } \\
\hline Economic Instrument & Advantages & Disadvantages \\
\hline 1. Standards and Quotas & & Not economically efficient \\
\hline 2. Water abstraction charges & $\begin{array}{l}\text { Adjustment of price signals } \\
\text { to reflect actual resource } \\
\text { costs; encourage new } \\
\text { technologies; flexibility; } \\
\text { generation of revenues }\end{array}$ & $\begin{array}{l}\text { Low charges will have } \\
\text { minimal impact on user } \\
\text { behaviour and will continue } \\
\text { in resource over-utilzation }\end{array}$ \\
\hline 3. Pollution charges & $\begin{array}{l}\text { Same as water abstraction } \\
\text { charges; polluter-pays } \\
\text { principle }\end{array}$ & $\begin{array}{l}\text { Same as water abstraction } \\
\text { charges }\end{array}$ \\
\hline 4. Subsidies & Readily acceptable & Not economically efficient \\
\hline 5. Tradable permits & Quantity based targets that & May entail high transaction \\
\hline
\end{tabular}




\begin{tabular}{|c|c|c|}
\hline & $\begin{array}{l}\text { are able to attain least-cost } \\
\text { outcome. Allows flexibility. }\end{array}$ & costs. \\
\hline 6. Voluntary agreements & Readily acceptable & \\
\hline 7. Liability legislation & $\begin{array}{l}\text { Assess and recover } \\
\text { damages ex-post but can } \\
\text { also act as prevention } \\
\text { incentives }\end{array}$ & $\begin{array}{l}\text { Require an advanced legal } \\
\text { system; high control costs; } \\
\text { burden of proof }\end{array}$ \\
\hline
\end{tabular}

\section{A Methodology for the Implementation of the Economic Aspects of the WFD}

In this section we outline the methodology we propose for application to the WFD. This methodology is based on 1) the identification of the appropriate unit for management; 2) the agreement of the objectives of water allocation 3) the evaluation of the various attributes of water demand within that unit; 4) the identification of optimal water resource allocations relative to objectives; 5) the assessment of the impacts of the proposed reallocation.

\section{1 The appropriate unit for management}

The watershed is a natural unit of analysis for addressing the balance of supply and demand for water, and the issues of efficiency, equity and sustainability for a number of reasons. First, the aggregate availability of water resources, including sustainable yields is bounded by the hydrological cycle of the watershed. Second, the interaction of different water sources (e.g. groundwater and surface water) is confined by the watershed. Third, the demands for water interact within the watershed and the hydrological impacts of one water user upon another and upon environment; that is, externalities are defined by the watershed. For these reasons, an understanding of the hydrological cycle in the watershed area in question is a pre-requisite for the determination of efficient, equitable and sustainable water resource allocation. 


\subsection{The objectives of water allocation}

Given the natural water resource constraints there is a clear need to address the pattern and growth of water demands in order to address the imbalance. The methodology proposed provides the policy maker and planner with an objective approach to balancing the competing demands for water subject to the natural constraints. The approach is based on the comparison of the economic value of water in different sectors, in terms of quantity and quality, in comparable units of measurement. The overall objective of public policy is to maximise societal welfare from a given natural resource base subject to those valuations. The key objectives of public policy in the allocation of resources are as follows:

- Efficiency: Economic efficiency is defined as an organisation of production and consumption such that all unambiguous possibilities for increasing economic wellbeing have been exhausted (Young 1996). For water, this is achieved where the marginal social benefits of water use are equated to the marginal social cost of supply, or for a given source, where the marginal social benefits of water use are equated across users.

- Equity: Social welfare is likely to depend upon the fairness of distribution of resources and impacts across society, as well as economic efficiency. Equal access to water resources, the distribution of property rights, and the distribution of the costs and benefits of policy interventions, are examples of equity considerations for water policy.

- Environment and Sustainability: The sustainable use of water resources has become another important aspect in determining the desirable allocation of water from the perspective of society. Consideration of intergenerational equity and the critical nature of ecological services provided by water resources provide two rationales for considering sustainability. In addition the in situ value and public good nature of water resources should enter into water allocation decisions. 


\subsection{The evaluation of water demand}

For physical, social and economic reasons, water is a classic non-marketed resource. Even as a direct consumption good, market prices for water are seldom available or when observable, often are subject to biases; subsidies, taxes etc. Similarly, environmental and ecological water values are rarely explicitly marketed and priced. Thus the economic value of water resources is seldom observed directly. The balancing of demands to resolve the resource conflicts described above requires the identification and comparison of the benefits and costs of water resource development and allocation among alternative and competing uses. In addition, water management policies have widespread effects on the quantity and quality of water within a watershed, and the timing and location of supplies for both in- and off-stream uses. In general, these impacts have an economic dimension, either positive or negative, which must be taken into account in policy formulation. Again, the value of these impacts is seldom observed directly.

Fortunately economists have refined a number of techniques to value water resources and address objectively the balance of demands and evaluate the impacts of water management policy. The first step towards the evaluation of economic benefits requires the identification of the demands for the resource. Water is needed for all economic and social activities, so the evaluator is faced with the problem of identifying a multi-sectoral demand curve. The dimensions of demand include municipal and industrial, agricultural, tourism and environmental (recreation, amenity and ecological).

The valuation of each of the identified demands calls for a different approach for two main reasons, a) the specific economic and hydrological context: data availability etc and b) because the use of the resource is sector-specific. The residential and tourist sectors exploit the use value of water and use it as a consumption good; the agricultural sector derives use value from water as an input in production. The value of water related environmental goods can be a use value or a non-use value, e.g. existence value. The overall evaluation strategy is shown in Figure 2.1 below.

The valuation techniques allow the estimation of the following desirable parameters: 
- Marginal Value of Water: The efficient balance of demands from a given source is found where the marginal value (benefit) of water is equated across users. In any given context efficiency is achieved where the marginal value of water is equated to marginal social cost

- Price Elasticities of Demand (PED): Measures the responsiveness of demand to price changes. Characterises the demand function and tells the policy maker the extent to which prices must change to cause demand to fall to a particular, e.g. efficient, sustainable, level.

- Income Elasticity of Demand (IED): Measures the extent to which the demand for water varies with income. Tells the policy maker whether water is a necessity or a luxury good and provides one way in which to assess the fairness of pricing policies. In combination with PED can be used to estimate welfare changes resulting from policies.

- Marginal/Average Willingness to Pay for Public Goods (WTP): Estimates the strength of demand for water as an environmental good. This determines in part the efficient environmental allocation of water

- Marginal Willingness to Pay for Quality Changes of Common Access Resources: Estimates the value of quality attributes of the resource, which are particularly important, if the resource is used as a productive input.

- Risk Parameters: Measurement of preferences towards risk and uncertainty. Useful for establishing policies, which reduce the impacts of risk on consumer groups occasioned by reason of variability in water availability.

\subsection{Balancing water demands in the watershed}


The outputs of the demand analysis allow the determination of the economically efficient allocations of water resources. The first element of an economically efficient allocation is the equi-marginal principle: this provides that each use of the water resource should achieve the same benefit from that water at the margin. In short, if water is more heavily valued at the margin in one sector than another, then it should be reallocated toward that sector until equality is achieved. The second element of the economically efficient allocation is that aggregate water resources are allocated efficiently where the marginal social benefit of their use is equated to the marginal social cost of supply.

One option for achieving an economically efficient water allocation is the use of the instrument of water pricing, where water is uniformly and universally charged at the marginal social cost of supply, which has the following implications. First, competing demands will each make use of the supply until its marginal benefit is equated with marginal social costs of supply (the equi-marginal principle). Note that this implies that every use must receive an equal marginal benefit from water resources. The second implication is that aggregate demand for water will expand until the marginal benefit is equated with the marginal social cost of supply (aggregate efficiency). Note that this implies that demand is endogenous and managed within this model. The third implication is that the key to the success of the policy is the determination of the appropriate marginal social cost of supply and the marginal benefits to environmental uses. Note that this implies that the methodology used for implementing the policy is as important as the method that is used for determining it.

\subsection{Deriving Policies from the Methodologies - Policy Impact Analysis}

There is a second phase to the water allocation methodology that flows from the consideration of the implementation of the conclusions from the first. First, the discussion here has largely been phrased in terms of the use of water pricing as the appropriate allocation mechanism, but this need not necessarily be the best or more appropriate instrument for allocating water in every context. There are many different approaches to enable the efficient allocation of water resources - pricing, marketable permits, even auctions. (Dinar 1996, Winpenny 1994, Easter et al 1999). Ultimately the 
particular context (watershed) must be considered for the feasibility of the various instruments, and the policy maker must determine the most appropriate allocation mechanism within that context.

Secondly, it is crucial to note that an economically efficient allocation need not necessarily be an equitable or sustainable one. Additional analysis is required to assess the distributional impacts of the allocation recommended by the equi-marginal principle. The hydrological impacts of the allocation need to be assessed, in order to assess whether the various demands are compatible within the existing watershed. Finally, the continued provision of basic environmental services within the watershed needs to be considered. In sum, the watershed needs to be double checked for unforeseen externalities and for missing markets for watershed services to ensure intra and inter-temporal efficiency is achieved and that equity and sustainability considerations are properly considered.

The methodology can be thought of as two complementary stages, the first consisting of an objective approach to ascertaining economically efficient water allocations and the latter phase consisting of the policy impact analysis. 
Figure The Methodology for Water Demand Valuation in a Watershed Area: Examples from the Kouris Watershed Case Study

\section{Valuing Water in a Watershed in the Absence of Market Prices}

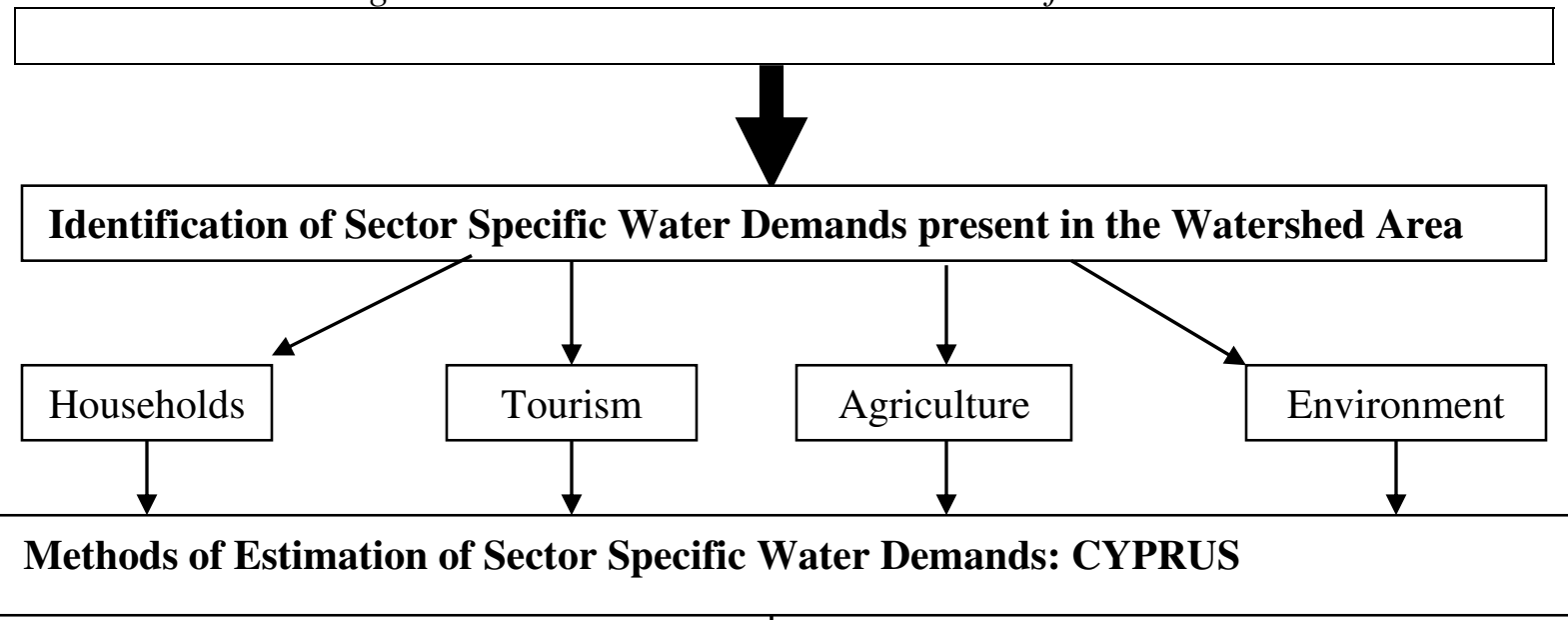

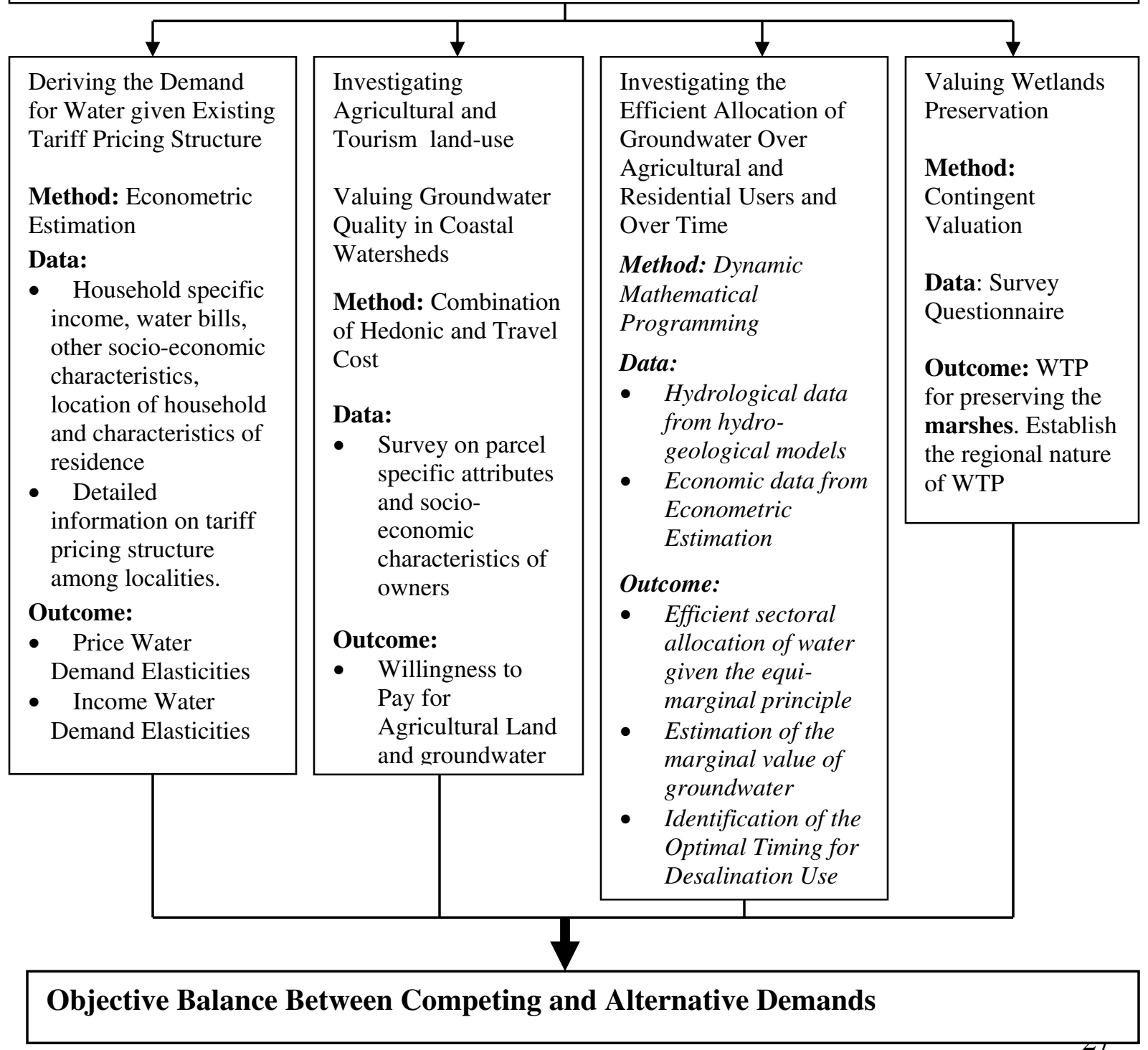




\section{6 Summary of Methodology}

\section{STAGE I: Objective Approach to Balancing Water Demands}

Evaluate Demands. Apply appropriate methodologies to assess characteristics of the demand for water arising from individual, sectoral and environmental uses. Derive the parameters of water demand required for policy purposes: Marginal Value, PED, IED, WTP, and risk parameters for all the relevant dimensions of demand. The evaluation process should be undertaken in accordance with carefully constructed methodologies, and be independent of any prior rights to water resources. This enables an evaluation of water uses according to the benefits that accrue to all of society from them.

Determine Efficient Allocations. Evaluate the relative values accruing to society by virtue of differing water allocations. Determine those water allocations that achieve an economically optimal balance. An economically optimal allocation is one in which aggregate demands are balanced with supply according to the equation of marginal social value (benefit) to the marginal social cost of supply, and in which each source of demand is achieving equal value from its marginal allocation of water.

Ascertain Impacts of Implementing Efficient Allocation. The policy maker may choose from a wide variety of instruments to effect the desirable allocation (tradable permits, pricing, auctions). Any proposed method of implementation should be considered for feasibility within the relevant watershed, and then evaluated for its broader impacts on the society. This evaluation process leads into Stage II of the Methodology.

STAGE II: Policy Impact Analysis

Welfare Distribution. The impact of the allocation policy options should be evaluated to establish the resulting distribution of the costs and benefits to society. That is, the change in social deadweight loss resulting from resource allocation changes should be 
determined, together with the actual distribution of this change. This is important both from the perspective of equity and often for reasons of political economy.

Market Failures and Missing Markets. Consideration of sectoral demands in isolation may be insufficient to ensure efficient outcomes. Where water users are conjoined by the underlying hydrology of the watershed there are a number of potential impacts/externalities that may arise from the chosen allocation. For example, policies implemented in upstream areas of a watershed will impact upon downstream users where the water resources are conjoined. Ignoring these effects will lead to inefficient allocations of water. In effect all the following facets of water demand should be considered: (a) Sectoral allocation, that is water demands should be balanced between sectors; (b) Spatial allocation, that is spatial variability and the conjoined nature of surface and groundwater; and (c) Temporal allocation, that is conjoined users may impose externalities upon each other relating to allocation over time and the timing of resource use. Other externalities arise from the demand for public goods, which frequently extends beyond the watershed. Global and regional environmental goods for which existence, bequest and option values are held provide an example of this. Furthermore, where water scarcity is extreme, demands for water outside the watershed may induce investments in inter-basin transfers.

Institutional and Legislative Analysis. As one of the main obstacles to water reallocations a review of the legislative and institutional environment required to effect the desired allocation may finally be required.

The methodology described above addresses the problem of water resource allocation at the level of the watershed and provides policy makers and resource managers with a concrete procedure for attaining economic efficiency targets whilst considering equity and environmental sustainability. The methodology proposes that competing demands, including the environment, are traded off against one another and balanced against extant hydrological constraints using the of notion of economic efficiency, the marginal valuation of water and the equi-marginal principle. The valuation exercises are 
undertaken independently of prevailing property rights regimes for water resources and hence allow the characterisation of efficient/optimal allocations of water, rather than those tainted by property rights uncertainties, open access and missing markets.

However, economic efficiency itself must be traded-off against the contributions to social welfare derived from equitable distributions of resources and policy impacts such as employment. Similarly the complex nature of hydrological linkages requires additional analysis to establish the value of water resources in non-marketed watershed services such as drought mitigation/risk reduction and coastal wetlands. In addition demands for in situ environmental services external to the watershed need to be considered along with other potentially subtle market failures. Where not addressed in Stage I, these considerations are captured by Stage II of the methodology. In sum, the integrated water resource management approach attempts to provide a coherent procedure for overcoming the water resource allocation problem addressed at the level of the watershed.

\section{Conclusion}

The importance of appropriate economic considerations in all aspects of water resources management is becoming increasingly recognized. This chapter has presented the necessary procedures for implementing an integrated approach from an economic perspective which consists of the characterization of the river basin, an assessment of current cost recovery, and the identification of economic instruments and measures that are able to evaluate the true economic cost of water (including financial, environmental and resource costs), and to provide policy-makers with the tools to allocate water in an efficient manner. The theory and applications of these valuation methods (hedonic pricing, travel cost methods, contingent valuations and choice modeling, among others) and the economic instruments (abstraction and pollution taxes, subsidies, and use of tradable permits) are described and illustrated with case studies.

Finally, we present a methodology for implementing the economic considerations of the EU Water Framework Directive. This takes into consideration the efficiency aspects of 
water allocation as well as the equity, environmental, and sustainability issues. Together, these can help to provide policy prescriptions that endeavor to provide an integrated water resources management framework.

\section{References}

Bockstael, N., Haneman, and Kling 1987. Estimating the Value of Water Quality

Improvements in A Rectreational Demand Framework. Water Resources Research 23 (5) 951-960.

Brouwer, R., Langford, I.H., Bateman, I., Turner, K. 2004 Meta-Analysis of Wetland Contingent Valuation Studies in Environmental Decision Making and Risk Management: Selected Essays by Ian H. Langford. Editor: Turner, R.K., Georgiou, S. and Bateman, I.J Edward Elgar Publishing, Cheltenham

Carlsson, F., Frykblom, P. and Liljenstolpe, C. (2003). 'Valuing wetland attributes: an application of choice experiments'. Ecological Economics 47, 95-103.

Groom, B., Koundouri, P., and T. Swanson, 2004. Efficient water allocation in Cyprus, in "Cost-Benefit Analysis and Water Resources Management" (eds. R. Brouwer and D. Pearce), Edward-Elgar Publishers. ISBN: 1843763591

Hadjispirou, S., Koundouri, P., and Pashardes, P., 2002. Household Demand and Welfare Implications of Water Pricing in Cyprus. Environment and Development Economics, 7(4): 659-685.

Hanley, N., Mourato, and Wright 2001. Choice Modelling Approaches: A superior alternative for environmental valuation? Journal of Economic Surveys 15(3): 435-462

Howitt, R. (1997). Market based conflict resolution. In Proceedings of the Rosenberg International Forum on Water Policy. Davis, CA: University of California, Water 


\section{Resources Center.}

Johannsen 2000 "Pricing Irrigation Water: A Literature Survey”. World Bank Policy Research Working Paper 2449

Koundouri, P., 2002. Groundwater and Economics, in "Groundwater", edited by Luis Silveira, in Encyclopedia of Life Support Systems (EOLSS), Developed under the Auspices of the UNESCO, Eolss Publishers, Oxford ,UK, [http://www.eolss.net E2-09toc.aspx]

Koundouri, P., 2004. Current Issues in the Economics of Groundwater Resource Management. Journal of Economic Surveys, 18(5): 703-740.

Koundouri, P., 2005. "Econometrics Informing Natural Resources Management: Selected Case Studies" Edward-Elgar Publishing, Wally Oates and Henk Folmer's 'New Horizons in Environmental Economics' Series. ISBN: 1843769220

Koundouri, P., 2005. "Water Policy Issues in Cyprus". Resources for the Future Press (forthcoming, Fall 2005).

Koundouri, P. and Groom, B., 2002. Groundwater Management: An Overview of Hydrogeology, Economic Values and Principles of Management, in "Groundwater”, edited by Luis Silveira, in Encyclopedia of Life Support Systems (EOLSS), Developed under the Auspices of the UNESCO, Eolss Publishers, Oxford ,UK, [http://www.eolss.net/E2-09toc.aspx]

Koundouri, P., and Pashardes, P., 2003. Hedonic Price Analysis and Selectivity Bias: Water Salinity and Demand for Land. Environmental and Resource Economics, 26 (1): $45-56$. 
Koundouri, P., Mantzou, K. and Mousoulides, M., 2004. European Water Management between Regulation and Competition: The case of Ireland, in "European Water Management between Regulation and Competition", A.A. Balkema, Rotterdam, The Netherlands, p. 189-209. ISBN: 9289464283

Koundouri, P., Pashardes, P., Swanson, T., and Xepapadeas, A., 2003. "Economics of Water Management in Developing Countries: Problems, Principles and Policies". Edward-Elgar Publishing. ISBN: 184376122X (278 pages)

Kraemer, A. and K. M. Banholzer (1999). Tradable Permits in Water Resource Management and Water Pollution Control, in Implementing Domestic Tradable Permits for Environmental Protection. OECD, Organisation for Economic Co-Operation and Development.

Kraemer, Kampa, and Interwies 2003. The Role of Tradable Permits in Water Pollution Control. Institute for International and European Environmental Policy.

Kraemer, Pielen, and Leipprand 2004. Economic Instruments for Water Management: Extra-Regional Experiences and their Applicability in Latin America and the Caribbean. Inter-American Development Bank, Washington , D.C., USA

Marino and Kemper 1999. Institutional Frameworks in Successful Water Markets: Brazil, Spain, and Colorado, U.S.A WB Technical Paper 427. World Bank

Mitchell and Carson 1989. Using Surveys to Value Public Goods: The Contingent Valuation Method. Baltimore MD. Johns Hopkins.

NOAA, 1993. Report of the NOAA Panel on Contingetn Valuation. Federal Register 58(10): 4601-14. Prepared by Arrow, Solow, Portney, Leamer, Radner and Schuman.

OECD 2002. Environmentally Related Taxes Database. www.oecd.org 
Pearce, D., and Koundouri, P., 2003. Diffusion Pollution and the Role of Agriculture, in “Water Sustainability and Regulation: The Next Periodic Review and Beyond” (eds. D. Helm), OXERA Press, p. 125-153. ISBN: 1873482426

Provenchur and Burt, 1993. The Externalities Associated with Common Property Resource Exploitation of Groundwater. Journal of Environmental Economics and Management, 24. 139-158.

Tao, W. e. a. (2000). "Tradable Discharge Permit System for Water Pollution: Case of the Upper Nanpan River of China." Environmental Resource Economics 15(1): 27-38.

Thobani, M. (1997). "Formal Water Markets: Why, When, and How to Introduce Tradable Water Rights." World Bank Research Observer 12(2): 161-79.

United Nation Environment Program, 2003. Vital Water Graphics. www.unep.org

Yaron 1997 “The Israel Water Experience: An Overview” in Parker and Tsur (eds) Decentralization and Coordination of Water Resources Management, Kluwer Academic Publishers, Boston.

Zilberman and Schoengold, 2005. The Use of Pricing and Markets in Water Allocation. Canadian Water Resources Journal. Vol. 30 (1) 1-10. 